\title{
AVALIAÇÃO NUTRICIONAL DO LEITE DE BÚFALA EM COMPARAÇÃO AO LEITE DE VACA
}

\author{
M.R. VERRUMA \\ Departamento de Ciencia e Tecnologia Agroindustrial - ESALQ/USP - C.P. 9, CEP:13418-900-Piracicaba,SP. \\ J.M. SALGADO \\ Departamento de Economia Doméstica - ESALQ/USP - C.P. 9, CEP:13418-900-Piracicaba,SP.
}

\begin{abstract}
RESUMO: Foi estudado o valor nutricional do leite de búfala integral e diluído em comparação com o leite de vaca integral e tipo $\mathbf{C}$, utilizando ratos como animais de teste, obtendo-se as seguintes conclusões: não houve diferença entre os leites estudados quanto à digestibilidade in vitro; a retenção de cálcio pelos animais, foi superior para a dieta com leite de búfala integral; não houve diferenças significativas para os níveis de triglicerideos no sangue dos animais; os nfveis de colesterol no sangue dos animais foram maiores para as dietas contendo leite de búfala, embora esses níveis sejam considerados dentro da faixa normal para os animais em estudo.
\end{abstract}

Descritores: leite de buifala, leite de vaca, avaliaçāo nutricional, $\mathrm{Ca}$, biodisponibilidade, colesterol, triglicerídeos

\section{NUTRICIONAL EVALUATION OF BUFFALO MILK IN RELATION TO COW MILK}

\begin{abstract}
The study of the nutritional value of whole and diluted buffalo milk in relation to whole and standardized cow milk was performed using rats as test animals. The following conclusions were obtained: no differences were observed between buffalo milk regarding in vitro digestibility; a higher calcium retention was exhibited by animals under diet of buffalo whole milk; trygliceride levels were higher in blood of rats under buffalo milk diet, although those values are considered to be nomal for these test animals.
\end{abstract}

Keg Words: buffalo milk, cow milk, evaluation nutrition, $\mathrm{Ca}$, biodisponibility, cholesterol, tryglicerides.

\section{INTRODUÇÃO}

Nos últimos 10 anos pensava-se que existissem cerca de 70 à 80.000 .000 cabeças de búfalos domésticos (Bubalus bubalis) no mundo; hoje, sabe-se que esta estimativa é bastante baixa, havendo diversos fatores que contribuem para esta avaliação inadequada (FAO, 1991).

Em alguns recenseamentos, os búfalos são incluídos como bovino, já em outras áreas os proprietários fornecem dados inferiores por questões fiscais ou não levam em consideração o número anual de plantéis (FAO, 1991), contribuindo para uma baixa avaliação do número de búfalos.

Os estudos de levantamentos feitos nas principais regiōes criadoras de búfalos, mostram que hoje deve existir cerca de 140.000 .000 cabeças de búfalos domésticos (FAO, 1991).

Com os conhecimentos atuais dos índices de produtividade e do valor nutritivo do leite de búfala, é evidente a existência de uma pecuária alternativa, tornando o leite de búfala valioso para o consumo in natura e na elaboração de derivados.

A utilização do leite na preparação de derivados tem sido muito pesquisada, em diferentes regiōes do mundo (LAXMINARAYANA \& DASTUR, 1968), por possuir em sua composição elevados teores de gordura, sólidos totais, proteína, cálcio e fósforo, consequentemente elevando os rendimentos na fabricação de queijos, produtos fermentados, leite em po, manteiga, leite matinizado, doce de leite e sorvete (FAO, 1991).

Levando em consideração estes fatores esta pequisa teve como objetivos o estudo do valor nutricional do leite de búfala integral e diluído em comparação com o leite de vaca integral e tipo $C$.

\section{MATERIAL E MÉTODOS}

Preparo das farinhas para o ensaio biologico e biodisponibilidade de cálcio

As amostras de leite foram evaporadas em estufa, com circulação forçada à $55^{\circ} \mathrm{C}$, até peso constante. Os materiais secos foram triturados em moinho de facas para obtenção das farinhas e posteriormente foram feitas análises de proteína utilizando a metodologia descrita em ASSOCIATION OF OFFICIAL ANALYTICAL 
CHEMISTS (1990). Em seguida formularam-se as dietas, a nível de $10 \%$ de proteína, empregando-se - método estabelecido pela ASSOCIATION OF OFFICIAL ANALYTICAL CHEMISTS (1990), com $10 \%$ de proteína, $4 \%$ da mistura salina, $1 \%$ de mistura vitamínica, $8 \%$ de 6 bleo na dieta de caseína. Nas dietas experimentais com leite, não se adicionou gordura, apenas a quantidade existente no leite.

\section{Ensaio biológico}

Foram utilizados no presente trabalho Rattus norvegicus variedade albinus, linhagem wistar, machos obtidos de cruzamentos sucessivos no biotério do setor de Nutrição Humana e Alimentos da Escola Superior de Agricultura "Luiz de Queiroz" da Universidade de São Paulo. Os animais tinham 21-23 dias de idade com uma variação de peso não mais que $5 \%$ dentro e entre grupos. Cada tratamento foi constituído por 6 animais os quais receberam um tratamento específico, como detalhado a seguir:

TRATAMENTO I: Leite de búfala integral

TRATAMENTO II: Leite de búfala diluído com $30 \%$ de água

TRATAMENTO III: Leite de vaca integral

TRATAMENTO IV: Leite de vaca tipo C

TRATAMENTO V: Dieta de caseína (Padrão)

TRATAMENTO VI: Dieta Aprotéica

Os animais permaneceram em gaiolas individuais, receberam água e alimentos ad libilum, sendo o peso e o consumo dos alimentos registrados três vezes por semana durante os 28 dias de duração do experimento. As fezes totais excretadas pelos ratos foram coletadas, secas em estufa a $105^{\circ} \mathrm{C}$ até peso constante, moídas e pesadas. Uma amostra das fezes de cada animal foi retirada para analisar o teor de nitrogênio, a fim de se calcular a digestibilidade. No vigésimo oitavo dia do experimento, apos jejum de 12 horas, todos os animais foram sacrificados. As cavidades abdominais, torácica e craniana foram abertas e secas em estufa a $105^{\circ} \mathrm{C}$, até peso constante. $\mathrm{O}$ material seco foi moído e o nitrogênio da carcaça foi determinado para o cálculo do NPU (Net Protein Utilization).
O nitrogênio das fezes e das carcaças foram determinadas pela técnica descrita em ASSOCIATION OF OFFICIAL ANALYTICAL CHEMISTS (1990).

A fim de corrigir a proteína consumida e eliminada, incluiu-se uma dieta aprotéica, para cálculo de digestibilidade e NPU.

Os cálculos foram feitos da seguinte forma:

Digestibilidade \% (D):

$D=\frac{P c-P e-P e a}{P c} \times 100$

onde $\mathrm{Pc}=$ proteína consumida, $\mathrm{Pe}=$ proteína excretada e Pea $=$ proteína excretada pelo grupo aprotéico, todos em 24 horas.

Net Protein Utilization \% (NPU):

$$
\mathrm{NPU}=\frac{[\mathrm{Bf}-(\mathrm{Bk}+\mathrm{Ik})]}{\text { If }} \times 100
$$

onde: $\mathrm{Bf}=$ nitrogênio da carcaça do grupo experimental, If $=$ nitrogênio ingerido, $\mathbf{B K}=$ nitrogênio da carcaça do grupo aprotéico, Ik = nitrogênio ingerido pelo grupo aprotéico, (MILLER \& BENDER, 1955).

Valor Biologico \% (VB):

V.B. $=\frac{\text { NPU }}{\text { If }} \times 100$

Protein Efficiency Ratio (PER):

$$
\begin{aligned}
& \text { PER }=\frac{G}{P} \\
& \text { onde } G=\text { ganho de peso }(g) \\
& P=\text { proteína ingerida }(p) \\
& \text { OSBORNE et al., 1919). }
\end{aligned}
$$




\section{AVALIAÇÃo NUTRICIONAL DO LEITE DE BÚFALA EM COMPARAÇÃO AO LEITE DE VACA}

Coeficiente de Eficiência Alimentar (CEA):

$\mathrm{CEA}=\frac{\mathrm{G}}{\mathrm{C}}$

onde $\mathrm{C}=$ consumo de ração.

\section{Digestibilidade in vitro}

As amostras dos leites foram submetidos à análise de proteína (ASSOCIATION OF OFFICIAL ANALYTICAL CHEMISTS, 1990) e em seguida foi feita a análise de digestibilidade in vitro, conforme metodologia descrita por AKESON \& STAHMANN (1964). Este método baseia-se na hidrólise enzímica das proteínas da amostra com pepsina e pancreatina, seguida da determinação da proteína digerida com ácido tricloroacético (T.C.A.).

\section{Biodisponibilidade de Cálcio em Ratos}

Foram utilizados no presente trabalho Rattus norvegicus variedade albinus, linhagem wistar.

Os animais tinham $21-23$ dias de idade com uma variação em peso não mais que $5 \%$. Cada tratamento continha 6 animais

A formulação das dietas foi feita de acordo com a ASSOCIATION OF OFFICIAL ANALYTICAL CHEMISTS (1990), sem O acréscimo de óleo nas dietas com leite, ficando apenas a gordura presente no leite e $8 \%$ de óleo na dieta de caseína. Para os níveis de cálcio foram os encontrados no leite, e na caseína acrescentou-se o necessário de $1,75 \mathrm{~g} / 100 \mathrm{~g}$ de dieta.

Os tratamentos empregados estão descritos a seguir:

TRATAMENTO I: Leite de búfala integral $(1,88 \mathrm{~g}$ $\mathrm{Ca} / 100 \mathrm{~g}$ de dieta)

TRATAMENTO II: Leite de búfala diluído com $30 \%$ de água $(1,26 \mathrm{~g} \mathrm{Ca} / 100 \mathrm{~g}$ da dieta)

TRATAMENTO III: Leite de vaca integral $(1,30 \mathrm{~g}$ $\mathrm{Ca} / 100 \mathrm{~g}$ da dieta)

TRATAMENTO IV: Leite de vaca tipo C $(1,45 \mathrm{~g}$ $\mathrm{Ca} / 100 \mathrm{~g}$ da dieta)

Sci. Agric., Piracicaba, 50(3):444-450, out./dez., 1993
TRATAMENTO V: Dieta padrão caseína $(1,75 \mathrm{~g}$ $\mathrm{Ca} / 100 \mathrm{~g}$ da dieta, exigida como padrão para o rato)

\section{TRATAMENTO VI: Dieta Aprotéica}

O teor de cálcio das dietas foi determinado através de espectrofotometria de absorção atômica (SARRUGE \& HAAG, 1979). Os animais permaneceram em gaiolas individuais, receberam alimentos ad libitum, sendo que o peso e o consumo dos alimentos foram registrados 3 vezes por semana durante 28 dias do experimento. As fezes foram coletadas e pesadas durante 4 semanas, e no final do experimento os animais foram sacrificados. Foram feitas as determinações de cálcio nas fezes de cada animal para se determinar a retenção do cálcio das dietas pelos animais.

No final deste ensaio também foi retirado uma alíquota de sangue dos animais para análise de colesterol e triglicérides.

Para análise de colesterol no sangue, utilizou-se o método enzimático, com leitura $\mathrm{em}$ espectrofotômetro a $505 \mathrm{~nm}$, baseado na metodologia descrita por TRINDER (1969), e para a análise de triglicérides no sangue utilizou-se a metodologia descrita por BUCOLO \& DAVID (1973).

\section{Análise estatística}

Para análise dos dados obtidos do ensaio biológico e disponibilidade de cálcio, aplicou-se a técnica de análise de variância, com utilização do teste Tukey $(5 \%)$ referente ao delineamento inteiramente casualizado adotado (GOMES, 1987).

\section{RESULTADOS E DISCUSS ÑO}

\section{Ensaio biológico}

O valor nutricional dos leites foram determinados por ensaio biológico, através dos parâmetros apresentados na TABELA 1.

Analisando estatisticamente, o parâmetro digestibilidade (D) observou-se que não houve diferenças significativas entre os tratamentos. Os dados para o leite de vaca integral estão de acordo com os dados obtidos por HENRY \& KON (1948).

Para o leite de búfala integral, DASTUR (1956) apresentou valores de $91,9 \%$ de digestibilidade estando de acordo com os dados obtidos nesse trabalho. 
TABELA 1 - Resultados da digestibilidade (D), utilização protéica líquida (NPU), valor biológico (VB), razão de eficiência protéica (PER) e coeficiente de eficiência alimentar (CEA) para dietas experimentais e padrão.

\begin{tabular}{lccccc}
\hline \hline & \multicolumn{5}{c}{ Parâmetros determinados } \\
\cline { 2 - 6 } Dietas & $\mathrm{D}(\%)$ & $\mathrm{NPU}(\%)$ & $\mathrm{VB}(\%)$ & PER & $\mathrm{CEA}$ \\
\hline Leite de búfala integral & $91,86 \mathrm{a}$ & $62,77 \mathrm{~b}$ & $68,33 \mathrm{~b}$ & $2,10 \mathrm{c}$ & $\mathbf{0 , 2 1 \mathrm { c }}$ \\
Leite de búfala diluído & & & & & \\
com 30\% de água & $92,31 \mathrm{a}$ & $70,93 \mathrm{ab}$ & $77,83 \mathrm{ab}$ & $2,20 \mathrm{c}$ & $\mathbf{0 , 2 1 \mathrm { c }}$ \\
Leite de vaca integral & $92,13 \mathrm{a}$ & $76,46 \mathrm{a}$ & $82,82 \mathrm{a}$ & $2,78 \mathrm{~b}$ & $0,27 \mathrm{~b}$ \\
Leite de vaca tipo C & $93,91 \mathrm{a}$ & $75,84 \mathrm{a}$ & $79,75 \mathrm{a}$ & $3,18 \mathrm{a}$ & $\mathbf{0 , 3 1 \mathrm { a }}$ \\
Caseína & $92,36 \mathrm{a}$ & $69,06 \mathrm{ab}$ & $74,77 \mathrm{ab}$ & $2,79 \mathrm{~b}$ & $0,27 \mathrm{~b}$ \\
\hline \hline
\end{tabular}

Médias seguidas por letras distintas diferem entre si ao nível de significância a 5\%.

Quanto aos valores da utilização protéica líquida (NPU), de acordo com a análise estatística realizada, o leite de búfala integral apresentou dados scmelhantes ao da caseína e leite de búfala diluído, enquanto estes dois últimos não apresentaram diferenças entre o leite de vaca integral e o tipo $\mathrm{C}$.

Os dados apresentados para o leite de vaca integral estão de acordo com o descrito por HENRY \& TOOTHILL (1962).

O valor biológico (VB) do leite de búfala integral foi semelhante ao da caseína e búfala diluído que não apresentaram diferenças significativas em relação às dietas de leite de vaca integral e tipo $\mathrm{C}$. Os dados obtidos para o leite de búfala e de vaca integrais são semelhantes aos citados por DASTUR (1956) e para o leite de vaca integral os resultados estão semelhantes aos descritos por LING et al. (1961); RASIC et al. (1971) e SOLÁ (1988). Os dados apresentados para a dieta de caseína estão semelhantes com LING et al. (1961) e LEHNINGER (1991).

Analisando os resultados obtidos para a taxa de eficiência protéica (PER) dos leites, verifica-se para o leite de vaca tipo $C$ houve diferenças significativas em relação aos demais. Para a caseína e leite de vaca integral os resultados foram semelhantes, porém superiores quando comparados aos leites de búfala integral e diluído. Os valores obtidos para o leite de búfala integral estão semelhantes aos obtidos por DASTUR (1956), enquanto que os citados por DANIEL et al. (1968) foram inferiores, e para o leite de vaca integral os dados estão semelhantes aos de COOK et al. (1951) e BRESSANI \& ARROYAVE (1963). Os resultados da dieta de caseína estão semelhantes com os trabalhos citados por LING et al. (1961).

Em relação ao coeficiente de eficiência alimentar (CEA), de acordo com a análise estatística, o leite de búfala integral apresentou resultados iguais ao de leite de búfala diluído, porém inferiores ao leite de vaca, integral, caseína e leite de vaca tipo C. Quanto ao consumo da ração, não houve diferença significativa entre os tratamentos, e, embora o consumo da ração fosse semelhante, o ganho de peso dos ani-mais foram diferentes, sendo que as dietas consti-tuídas de leite de búfala integral e diluído foram as em que os animais apresentaram menor peso entre os tratamentos, mostrando que o elevado teor de gordura existente, não elevou o peso corporal.

\section{Digestibilidade in vitro}

Os dados de digestibilidade in vitro estão dispostos na TABELA 2. De acordo com os dados obtidos não houve diferença entre os valores de digestibilidade pelo método químico e biológico, mostrando que há uma correlação positiva entre os métodos analisados. Os valores obtidos para o leite de vaca integral foram inferiores aos obtidos por AKESON \& STAHMANN (1964). 
TABELA 2 - Dados de digestibilidade da proteína in vitro dos leites.

\begin{tabular}{lcc}
\hline \hline & \multicolumn{2}{c}{ Parâmetros avaliados } \\
\cline { 2 - 3 } Amostras & Proteína (\%) & Digestibilidade in vitro (\%) \\
\hline Leite de búfala integral & 26,60 & 90,2 \\
Leite de búfala diluído & 25,20 & 90,2 \\
Leite de vaca integral & 25,40 & 90,0 \\
Leite de vaca tipo C & 23,40 & 90,0 \\
\hline \hline
\end{tabular}

" Proteína total em base seca.

\section{Biodisponibilidade de Cálcio dos Ratos}

Através do ensaio de biodisponibilidade de cálcio em ratos alimentados com as dietas experimentais e dieta padrão caseína, foi possível calcular os parâmetros descritos na TABELA 3.

$\mathrm{Na}$ composição das dietas, os teores de cálcio foram apenas os existentes nos leites $\mathrm{em}$ estudo e para caseína utilizou-se o padrão de cálcio para ratos de acordo com ASSOCIATION OF OFFICIAL ANALYTICAL CHEMISTS (1990).

Para os níveis de cálcio retido pelos animais, a dieta com leite de búfala integral apresentou maiores médias, obtendo valores semelhantes ao da caseína. Os resultados obtidos para cálcio retido pelos animais alimentados com dieta de caseína foram semelhantes às dietas de leite de vaca tipo $\mathrm{C}$ e leite de búfala diluído, que não diferenciaram da dieta com leite de vaca integral.

De acordo com COSTA (1947), a retenção de cálcio em animais com leite de vaca foi $87 \%$, valor inferior ao citado no presente trabalho.

Conforme visto na TABELA 3 , as diferenças de retenção de cálcio nas dietas foram mínimas, demonstrando que a pasteurização do leite de vaca tipo $C$ não interferiu na biodisponibilidade de cálcio.

Estes resultados podem estar relacionados com os componentes existentes na dieta, favorecendo a biodisponibilidade do cálcio. Um dos fatores que provavelmente favorece esta alta retenção de cálcio nas dietas experimentais é o alto teor de proteína e cálcio, exercendo efeitos estimuladores através de aminoácidos, principalmente a lisina, arginina e peptídeos formando quelatos solúveis com o cálcio (WASSERMAN et al., 1956; McBEAN \& SPACKMANN, 1974; SOLÁ, 1988).

No mesmo ensaio foi retirado o sangue dos animais para determinação de colesterol e triglicérideos, os resultados estão dispostos na TABELA 4.

De acordo com os valores obtidos para os níveis de triglicerídeos no sangue dos animais alimentados com as dietas experimentais, não houve diferença significativa entre os tratamentos.

Para os níveis de colesterol, houve diferenças significativas, uma vez que o leite de búfala integral e búfala diluído, apresentaram valores semelhantes, sendo maiores que os obtidos para as dietas de leite de vaca integral, tipo $\mathrm{C}$ e caseína.

De acordo com BOYD (1942), o colesterol total presente no plasma de ratos varia de 28 a $76 \mathrm{mg} / 100 \mathrm{ml}$ com uma média de $52 \mathrm{mg} / 100 \mathrm{ml}$, demonstrando que as dietas experimentais não elevaram o nível normal de colesterol no plasma dos ratos.

Este valor mais alto de colesterol no plasma de ratos alimentados com os leites de búfala deve estar associado com o elevado teor de gordura no leite de búfala e a sua composição de ácidos graxos saturados como o palmítico e esteárico, os quais, de acordo com literaturas, elevam o colesterol no sangue.

\section{CONCLUSÕES}

- Não houve diferenças entre os leites estudados quanto à digestibilidade in vitro; 
TABELA 3 - Resultados obtidos no ensaio de biodisponibilidade de cálcio.

\begin{tabular}{lccccc}
\hline \hline \multirow{2}{*}{$\begin{array}{l}\text { Parâmetros } \\
\text { avaliados } \\
(\%)\end{array}$} & $\begin{array}{c}\text { Lúfala } \\
\text { integral }\end{array}$ & $\begin{array}{c}\text { Búfala } \\
\text { diluído }\end{array}$ & $\begin{array}{c}\text { Vaca } \\
\text { integral }\end{array}$ & $\begin{array}{l}\text { Vaca } \\
\text { tipo C }\end{array}$ & Caseína \\
\hline $\begin{array}{lccccc}\text { Ca na dieta } \\
\text { Ca retido p/ratos }\end{array}$ & 1,88 & 1,26 & 1,30 & 1,45 & 1,45 \\
\hline \hline
\end{tabular}

Médias seguidas de letras distintas diferem entre si, pelo teste de Tukey, ao nível de $5 \%$ de significância.

TABELA 4 - Resultados dos valores obtidos para colesterol e triglicerídeos no sangue dos animais.

\begin{tabular}{lcc}
\hline \hline & \multicolumn{2}{c}{ Parâmetros determinados (mg/100ml) } \\
\cline { 2 - 3 } Dietas & Triglicerídeos & Colesterol \\
\hline Leite de búfala integral & $85,50 \mathrm{a}$ & $64,27 \mathrm{a}$ \\
Leite de búfala diluído & $73,37 \mathrm{a}$ & $58,10 \mathrm{a}$ \\
Leite de vaca integral & $78,17 \mathrm{a}$ & $45,53 \mathrm{~b}$ \\
Leite de vaca tipo C & $69,92 \mathrm{a}$ & $46,70 \mathrm{~b}$ \\
Caseína & $74,37 \mathrm{a}$ & $46,53 \mathrm{~b}$ \\
\hline \hline
\end{tabular}

Médias seguidas por letras distintas diferem entre si ao nível de $5 \%$ de significância.

- A retenção de cálcio pelos animais foi superior para a dieta com leite de búfala integral;

- O leite de búfala integral e diluído apresentaram características nutricionais satisfatórias para 0 consumo humano.

\section{REFERÊNCIAS BIBLIOGRÁFICAS}

AKESON, W.R.; STAHMANN, M.A. A pepsin pancreatin digest index of protein quality evaluation. Journal of Nutrition, Bethesda, v.83, n.3, p.257-61, 1964.

ASSOCIATION OF OFFICIAL ANALYTICAL CHEMISTS. Official methods of analysis. 15.ed. Washington, 1990. 2v.
BOYD, E.M. Species variation in normal plasma lipids estimated by oxidative micromethods. Joumal of Biological Chemistry, Baltimore, v.143, p.131-132, 1942.

BRESSANI, R.; ARROYANE, R. Nutritive value of pumpkin seed. Essential amino acid content and protein value of pumpkin seed (Curcubita farinosa). Journal of Agricultural and Food Chemistry, Washington, v.11, n.1, p.29-33, 1963.

BUCOLO, G.; DAVID, H. Quantitative determination of serum triglycerides by the use of enzymes. Clinical Chemistry, New York, v.19, n.5, p.476-482, 1973.

COOK, B.B.; MORGAN, A.F.; WEAST, E.O.; PARKER, J. The effect of heat treatment on the nutritive value of milk proteins. I. Evaporated and powered milks. Journal of Nutrition, Bethesda, v.44, p.51-61, 1951 . 
COSTA, D. Tratado de nutrição. Rio de Janeiro: Guanabara, 1947.630p.

DANIEL, V.A.; DESAI, B.L.M.; VENKAT RAO, S.; SWAMINATHAN, M.; PARPIA, H.A.B. The nutritive value of humanized milk food based on buffalo milk and fortified with DL-methionine. Journal of Food Science, Chicago, v.33, p.331-334. 1968.

DASTUR, N.N. Buffaloes'milk and milk products. Dairy Science Abstracts, Wallingford, v.18, n.121, p.967-1008, Dec. 1956.

FAO. $O$ búfalo. Brasinia: Ministério da Agricultura. São Paulo: Associação Brasileira dos Criadores de Búfalos, 1991. 320p. (FAO. Produção Animal e Saúde, 4.)

GOMES, F.P. Curso de estatística experimental. 10ed. São Paulo: Nobel, 1987. 430p.

HENRY, K.M.; KON, S.K. Changes in the biological value of the proteins. IV. Journal of Dairy Research, Cambridge, v.15, n.3, p.341-346, 1948.

HENRY, K.M.; TOOTHILL, J. A comparison of the body-water and nitrogen balance - sheet methods of determining the nutritive value of proteins. British Journal of Nutrition. Cambridge, v.16, p.125-133, 1962.

LAXMINARAYANA, H. \& DASTUR, N.N. Buffaloes'milk and milk products. I. Dairy Science Abstracts, Wallingford, v.30, n.4. p.177-186, 1968.

LEHNINGER, A.L. Princípios da bioquímica. São Paulo: Sarvier, 1991.752p.

LING, E.R.; KON, S.K.; PORTER, J.W.G. The composition of the milk and nutritive value of its componentes. In: KON, S.K.; COWIE, A.T. Milk: the mamary gland and its secretion. New York: Academic Press, 1961. v.2., cap. 17, p.195-263.
McBEAN, L.D.; SPACKMANN, E.W. A recognition of the interrelationship of calcium with various dietary componentes. American Journal of Clinical Nutrition, New York, v.6, p.603-609, 1974.

MILLER, D.S.; BENDER, A.C. The determination of net utilization of protein by shostened method. British Journal of Nutrition, Cambridge, v.9, p.382-383, 1955.

OSBORNE, T.B.; MENDEL, L.B.; FERRY, E.L. A method of expressing numerically the growth promoting value of proteins. Journal of Biological Chemistry, Baltimore, v.37, p.223-229, 1919.

RASIC, J.; STOJSAVLJEVIC, T.; CUURCIC, R. A study on the amino acids of yogurt. II. Amino acids content and biological value of proteins of different kinds of yogurt. Milchwissenschaft. Nurnberg, v.26, n.4, p.219-224, 1971.

SARRUGE, J.R.: HAAG, H.P. Analises químicas em plantas. Piracicaba:ESALQ, 1979. 40p.

SOLÁ, J.E. Manual da dietoterapia do adulto. 6.ed. Rio de Janeiro, Atheneu, 1988. 550p.

TRINDER, P. Determination of glucose in blood using glucose oxidase with an alternative oxygen acceptor. Annals of Clinical Biochemistry. London. v.6. p.24-27, 1969.

WASSERMAN, R.H.; COMAR, C L.: NOLD. M.M. The influence of amino acids other organic compounds on the gastointestinal absorption of calcium and strontium in the rat. Journal of Nutrition. Bethesda. v.59, p.371-383, 1956 .

Enviado para publicação $\mathrm{em} 28.07 .93$

Aceito para publicação em 20.09.93 